\section{Improving oral healthcare for children - a great opportunity}

S. Fayle ${ }^{1}$
IN BRIEF
- Discusses how forthcoming changes in commissioning and contracting of NHS dental services in England will provide both challenges and opportunities for children's oral healthcare delivery.
- Emphasises the importance of securing effective delivery of prevention, and ensuring that children with highest need can easily and equitably access appropriate oral healthcare.

Changes in commissioning and contracting of NHS dental services will impact on oral healthcare delivery, providing new challenges and opportunities for children's oral healthcare. Now is the time to assess clinical networks and specialised services to understand how the oral healthcare needs of all children can be met appropriately and effectively so that when change comes it can be embraced for the better.

Changes to the wider National Health Service in England are driving a redesign of how oral healthcare will be delivered in the future. In addition to the development of a new NHS general dental practice (GDS) contract, reconfiguration and rationalisation of services for those patients whose needs fall beyond the remit of the GDS is also being revised. The Steele report ${ }^{1}$ emphasised the need to focus on improved oral health as the outcome for NHS dental services and current changes offer a great opportunity to make this aspiration a reality for the children of England.

Dental caries remains one of the most prevalent disease conditions in our child population. No other disease in childhood is so prevalent that it is traditionally quantified by quoting 'average' levels across an entire age cohort (ie dmf). While considerable reductions in the prevalence of childhood caries have been seen over the past four decades, the greatest improvements have been seen in older children, with caries levels in five-year-olds remaining virtually unchanged. ${ }^{2}$

For many young children, dental caries is associated with considerable morbidity. Several studies published over the past

Consultant in Paediatric Dentistry, Leeds Denta Institute, Clarendon Way, Leeds, LS2 9LU

Correspondence to: Stephen Fayle

Email:s.a.fayle@leeds.ac.uk

Accepted 21 February 2013

DOI: 10.1038/sj.bdj.2013.528

${ }^{\ominus}$ British Dental Journal 2013; 214: 547-549 decade or so have demonstrated that pain and infection are common sequelae. ${ }^{3,4}$ It is therefore not surprising that dental treatment is currently the fourth most common reason why a child is admitted to hospital in England. ${ }^{5}$ Others have reported additional potential impacts on child wellbeing, ${ }^{6,7}$ with affected children being lighter and smaller. ${ }^{8-11}$ The impact on families can also be significant. ${ }^{12,13}$

Current evidence suggests that GDS practitioners can struggle to successfully manage such children, with significant morbidity being a common sequela, even in regularly attending children. ${ }^{14}$ Studies in some parts of the UK have also failed to demonstrate any real benefit from restorative care provided in GDS practice for primary teeth ${ }^{15}$ in spite of an evergrowing body of evidence that appropriate restorative/surgical interventions can have a positive outcome in the primary dentition, ${ }^{16,17}$ especially when coupled with effectively delivered prevention. The management of children with extensive disease is often also complicated by anxiety and age, making effective management much more than simply a technical challenge and increasing the time required for effective treatment to be successfully delivered.

Reorganisation of dental services in England offers the opportunity for a rethink of how best to meet these challenges. Effective management of the child with dental caries requires access to a full range of management options. Coronal dental caries is essentially a childhood disease, and preventive care should underpin its management. Health promotion and prevention of disease in childhood has an obvious payoff ${ }^{18}$ and yet the systems within UK NHS dentistry have, over the past few decades, worked to promote cycles of intervention and repair that Steele describes as a 'legacy of a different age.' ${ }^{1}$ Preventive care should be relatively straightforwardly provided in general dental practice for all children, using the excellent evidence-based toolkit included in Delivering better oral health. ${ }^{19}$ The challenge now is to translate this into a framework that enables and promotes successful delivery of prevention within the GDS.

For those children requiring restorative and/or surgical interventions, ensuring that those delivering care have appropriate training and skills is key. While generalist dentists are undoubtedly able to manage children at the more straightforward end of the spectrum, many children, especially the young, the anxious and the child with extensive disease, require referral for more specialised management. While there has been much debate over the years about where this 'cut-off' should be, the key measure of effective management should be good, stable oral health, with the child being maintained free from pain and infection. Where this cannot be achieved surely the child requires more specialised management?

To ensure children requiring more specialised management can move efficiently 
to the right level of care, as recommended by Darzi, ${ }^{20}$ well organised and integrated networks are essential. Such poly-systems need a full range of services, skilled professionals to provide them and should ultimately be specialist/consultant led. However, this does not mean that all care for children with higher needs should be provided directly by specialists - far from it: practitioners with enhanced skills and other dental care professionals could play a valuable role in the management of many such children. If enhanced practitioners are to be developed then any new funding framework must recognise the extra time and skill that effective management of such children requires and appropriate training programmes will need to be designed. Also, the availability of dental therapists and dental nurses with extended duties offers a great opportunity to balance maximum economy with quality, both for preventive and restorative/surgical care. This concept has been successfully adopted by paediatric dentists elsewhere in the world, largely in countries where effective publicly-funded oral healthcare is not available, with quality at the best price being prime drivers. Specialist services will also play a key role. Clinical leadership provided by appropriately trained specialists/consultants would enhance support for the whole network, while also ensuring that a full range of effective and high quality services is developed and available.

In most parts of the country, the salaried (previously 'community') dental services (SDS) have traditionally provided care for children whose needs fall out with the remit of the GDS, and over the last two decades some SDS have significantly developed their specialist children's services to meet this need. However, many SDS have undergone radical change in recent years, and there is currently (justifiably) increasing emphasis on adults and children with significant disability or co-morbidity (traditionally referred to as 'special needs'). Unfortunately this has been accompanied, in many services, by declining emphasis on the otherwise 'healthy' child. In a recent survey carried out by the BSPD, 20\% of SDS-based members reported that there had been recent or planned loss of paediatric dentistry posts in their locality, suggesting that this trend is continuing. ${ }^{21}$ The 2010 Kennedy report ${ }^{18}$ in reviewing barriers within paediatric services emphasised the importance of having 'at least one professional who has specialised knowledge in the comprehensive care of children and young people' in all child-care poly-systems. In spite of this, the skill-mix within the SDS and the services provided varies considerably across the country and surprisingly many SDS still have no paediatric dentists on their staff.

One field where specialists can have the greatest impact is the planning and provision of dental care under general anaesthesia. While historically there has been (rightly) much emphasis on the risks and safety of the general anaesthetic component of these services, with appropriate reconfigurations being made there has been less of a focus on the quality of the oral healthcare provided (which after all is our prime role). Dentistry under general anaesthesia (DGA) is one of the highest risk and most expensive services for children's oral healthcare we provide and so it would seem logical to ensure it is planned and delivered as efficiently and effectively as possible. Current evidence demonstrates excellent outcomes from specialist-led (DGA) services, ${ }^{22-24}$ with audits of UK-based specialist-led services demonstrating some of the lowest repeat-rates in the world..$^{25-27}$ And yet remarkably many services providing DGA for children still have no specialist input. Equally remarkable is that in many parts of the UK restorative treatment under GA is restricted to children with disability or co-morbidity, effectively excluding access of many young and anxious children to these important services.

\section{CONCLUSION}

To meet current challenges we need to carefully consider how best to design an integrated network of services with an appropriate range of skills and services to most effectively meet childrens' oral health needs and service design should aim to facilitate easy access for those children who may have highest need. Effective commissioning of prevention, the potential for the development of enhanced practitioners and the wider use of other dental professionals needs to be considered. Finally, all networks and poly-systems need to be ultimately specialist/consultant-led, as such individuals have the training and expertise to engage with and support dental professionals and commissioners to ensure a full range of integrated, efficient and effective services is available. Access to specialised services must be equitable across the country and the critical role of primary care based SDS in this field must be recognised and enhanced.

Getting it right will not be easy and will require all oral health professionals to engage in the process and embrace appropriate change, but surely children deserve nothing less.

1. Steele J, Clarke J, Wilson T, Rooney E. NHS dental services in England: an independent review led by Professor Jimmy Steele. London: Department of Health, 2009.

2. Pitts N B, Boyles J, Nugent Z J, Thomas N, Pine C M. The dental caries experience of 5 -year-old children in Great Britain (2005/6). Surveys coordinated by the British Association for the study of community dentistry. Community Dent Health 2007; 24: 59-63.

3. Milsom K M, Tickle M, Blinkhorn A S. Dental pain and dental treatment of young children attending the general dental service. Br Dent J 2002; 192: 280-284.

4. Levine R S, Nugent Z J, Pitts N B. Pain prediction for preventive non-operative management of dentina caries in primary teeth in general dental practice. Br Dent J 2003; 195: 202-206.

5. Hansard. Written answers. Hospitals: admissions (Parliamentary debates 16 April 2012). House of Commons Official Report 2012; 543: 116W. Online debates available at http://www.publications. parliament.uk/pa/cm201212/cmhansrd/chan288.pdf (accessed April 2013)

6. Low W, Tan S, Schwartz S. The effect of severe caries on the quality of life in young children. Pediatr Dent 1999; 21: 325-326.

7. Pahel B T, Rozier R G, Slade G D. Parental perceptions of children's oral health: the Early Childhood Oral Health Impact Scale (ECOHIS). Health Qual Life Outcomes 2007; 5 : 6 .

8. Acs G, Lodolini G, Kaminsky S, Cisneros G J. Effect of nursing caries on body weight in a pediatric population. Pediatr Dent 1992; 14: 302-305.

9. Ayhan H, Suskan E, Yildirim S. The effect of nursing or rampant caries on height, body weight and head circumference. J Clin Pediatr Dent 1996; 20 209-212.

10. Sheiham A. Dental caries affects body weight growth and quality of life in pre-school children. Br Dent J 2006; 201: 625-626.

11. Benzian $H_{\text {, Monse }}$, Heinrich-Weltzien $\mathrm{R}$ Hobdell M, Mulder J, van Palenstein Helderman W. Untreated severe dental decay: a neglected determinant of low body mass index in 12-year-old Filipino children. BMC Public Health 2011; 11: 558.

12. Locker D, Jokovic A, Stephens M, Kenny D, Tompson $B$, Guyatt G. Family impact of child oral and orofacial conditions. Community Dent Oral Epidemiol 2002; 30: 438-448.

13. Tsakos G, Blair Y I, Yusuf H, Wright W, Watt R G, Macpherson L M. Developing a new self-reported scale of oral health outcomes for 5 -year-old children (SOHO-5). Health and Quality of Life Outcomes 2012; 10: 62.

14. Tickle M, Blinkhorn A S, Milsom K M. The occurrence of dental pain and extractions over a 3-year period in a cohort of children aged 3-6 years. J Public Health Dent 2008: 68: 63-69.

15. Tickle M, Milsom K, King D, Kearney-Mitchell $P$, Blinkhorn A S. (2002). The fate of the carious primary teeth of children who regularly attend the general dental service. Br Dent J 2002; 192: 219-223.

16. Innes N P, Evans D J, Stirrups D R. The Hall Technique; a randomized controlled clinical trial 
of a novel method of managing carious primary molars in general dental practice: acceptability of the technique and outcomes at 23 months BMC Oral Health 2007; 7: 18.

17. Roberts J F, Attari N, Sherriff M. The survival of resin modified glass ionomer and stainless stee crown restorations in primary molars, placed in a specialist paediatric dental practice. Br Dent J 2005; 198: 427-431.

18. Kennedy I. Getting it right for children and young people: overcoming cultural barriers in the NHS so as to meet their needs. A review by Professor Sir lan Kennedy. London: Department of Health, 2010.

19. Department of Health, British Association for the Study of Community Dentistry. Delivering better oral health: an evidence based tool kit for prevention, 2nd ed. London: DH, 2009.

20. Darzi A. High quality care for all: NHS next stage review (final report). London: Department of Health 2008

21. British Society of Paediatric Dentistry. Report of BSPD members' survey in response to 'Transforming community services.' London: BSPD, 2011. Online report available at http://www.bspd.co.uk/LinkClick. aspx?fileticket $=A$ LrXOqLOxOM\%3D\&tabid $=40$ (accessed April 2013).

22. Cunnion D T, Spiro A 3rd, Jones J A. Pediatric oral health-related quality of life improvement after treatment of early childhood caries: a prospective multisite study. J Dent Child (Chic) 2010; 77: 4-11.

23. Acs G, Shulman R, Ng M W, Chussid S. The effect of dental rehabilitation on the body weight of children with early childhood caries. Pediatr Dent 1999; 21: 109-113.

24. Anderson H K, Drummond B K, Thomson W M. Changes in aspects of children's oral-health-related quality of life following dental treatment under general anaesthesia. Int J Paediatr Dent 2004; 14: 317-325.

25. Kakaounaki E, Tahmassebi J F, Fayle S A. Repeat general anaesthesia, a 6-year follow up. Int J Paediatr Dent 2011; 21: 126-131.

26. Grant S M, Davidson L E, Livesey S. Trends in exodontia under general anaesthesia at a dental teaching hospital. Br Dent J 1998; 185: 347-352

27. Albadri S S, Jarad F D, Lee G T, Mackie I C. The frequency of repeat general anaesthesia for teeth extractions in children. Int J Paediatr Dent 2006; 16: $45-48$. 